УДК 62-77

05.00.00 Технические науки

МОДЕЛИРОВАНИЕ ПАРАМЕТРОВ МАЛОГАБАРИТНОГО АГРЕГАТА ТЕХНИЧЕСКОГО ОБЛУЖИВАНИЯ

Никитченко Сергей Леонидович

к.т.н., доцент

РИНЦ SPIN-код=3384-0973

Смыков Сергей Владимирович аспирант

РИНЦ SPIN-код=5670-2012

Азово-Черноморский инженерный

институт ФГБОУ ВО «Донской

государственный аграрный

университет», Зерноград, Россия

В статье рассмотрен комплексный математический подход к моделированию функциональных и структурных параметров мобильных средств технического сервиса, а также технико-экономических показателей их работы. Авторами предложены критерии оценки и структурная схема малогабаритного агрегата технического обслуживания машин. Для навесного варианта агрегата описан метод компоновки сервисной оснастки и выполнен анализ себестоимости сервисных работ в сравнении с прицепными аналогами

КлючевЫе слова: АГРЕГАТ ТЕХНИЧЕСКОГО ОБСЛУЖИВАНИЯ, МАТЕМАТИЧЕСКАЯ МОДЕЛЬ, КОНФИГУРАТОР, АЛГОРИТМ КОМПОНОВКИ, СЕБЕСТОИМОСТЬ СЕРВИСНЫХ РАБОТ

Doi: 10.21515/1990-4665-121-032
UDC $62-77$

Technical sciences

\section{THE SMALL SIZED UNIT MAINTENANCE} MODELING

\author{
Nikitchenko Sergey Leonidovich \\ Cand.Tech.Sci., assistant professor \\ RSCI SPIN-code=3384-0973
}

Smykov Sergey Vladimirovich graduate RSCI SPIN-code $=5670-2012$ The Azov-Black sea engineering institute FSBEE HE "Donskoy state agrarian university", Zernograd, Russia

An integrated mathematical approach to modeling functional and structural parameters of a mobile technical service was observed in the article, and also, we reviewed their technical and economical work indicators. The authors propose evaluation criteria and the structural scheme of small sized units of technical service machines. For the attached unit option a combining service snap method is described and the service cost analysis in comparison with trailed analogues is made

Keywords: TECHNICAL SERVICE UNIT, MATHEMATICAL MODEL, CONFIGURATOR, LAYOUT ALGORITHM, COST OF MAINTENANCE WORK

\title{
Введение
}

В настоящее время практически отсутствует системный математический подход, позволяющий решать задачи параметрического синтеза мобильных сервисных средств и моделировать технико-экономические показатели их работы в заданных производственных условиях. Данная статья содержит математическую постановку этих задач и этапы их решения, что подчёркивает её научную новизну. Целью данной работы является обоснование параметров малогабаритного мобильного агрегата для технического обслуживания (АТО) сельскохозяйственной техники. В качестве предмета 
исследований авторы рассматривали влияние функционального назначения АТО, характеристик применяемой сервисной оснастки и условий производства на структурные параметры, а также технологические и техникоэкономические показатели сервисного средства.

\section{Состояние исследований и актуальность работы}

В обязательства дилерских сервисных служб не входит выполнение операций ежесменных технических обслуживаний (ETO) и номерных ТО-1 машин. Эти работы владельцы сельскохозяйственной техники вынуждены выполнять своими силами. Оперативность данных работ существенно повышается, если они выполняются на местах работы машин с использованием АТО. В современном сельскохозяйственном производстве практически не осталось серийных АТО с типовым набором оснастки [5, 7]. Хозяйства в основном используют агрегаты на тракторных прицепах, которые изготавливают собственными силами, что не всегда отвечает требованиям безопасности и экологичности. Серийные АТО на шасси автомобиля или на тракторном прицепе практически не приобретаются сельхозтоваропроизводителями в силу их громоздкости и дороговизны. В этой связи актуальным становится вопрос создания малогабаритного АТО с минимально необходимым набором функций и соответствующей сервисной оснастки.

\section{Постановка и решение задач}

Рассмотренный в данной статье системный подход к обоснованию параметров агрегатов технического обслуживания включает следующие этапы - обоснование функциональности, выбор оснастки и типа сервисного средства, оптимальную компоновку оснастки на несущей раме и технико-экономическую оценку проектируемого объекта.

Применительно к полевым условиям сельхозпредприятий и крестьянско-фермерских хозяйств (КФХ) функциональные возможности АТО должны позволить выполнять ЕТО и номерное техническое обслуживание ТО-1, а также устранять несложные отказы машин с применением металл- 
орежущего, слесарного и универсального инструмента. Такая функциональность перспективных сервисных средств доказана практикой прошлых лет, которая показала, что серийные агрегаты АТО-9994 и АТО-4822 практически не использовались для выполнения операций ТО-2 в полевых условиях хозяйств - эти работы выполнялись в стационарных условиях. Оснастка для ТО-2, устанавливаемая на серийных АТО, делает их громоздкими и дорогими, и при этом является избыточной.

Модель оптимизации типа и оснастки сервисного средства содержит абстрактное и функциональное описание объекта.

Абстрактное описание сервисного средства представим в виде системы $S$ как произведение множеств:

$$
S \subseteq D \times M \times R=\left\{(d, m, r) \mid d_{i} \in D, m_{i} \in M, r_{i} \in R\right\}
$$

где $S$ - система передвижное сервисное средство;

$D$ - множество оснастки сервисного средства;

$M$ - множество марок обслуживаемых машин;

$R$ - множество операций ТО и устранения отказов (виды работ, кото-

рые можно выполнять с помощью сервисного средства).

Для выражения (1) имеют место отображения:

$\alpha: D \rightarrow R-$ множество оснастки сервисного средства есть отображение множества выполняемых операций;

$\beta: R \rightarrow M-$ множество операций ТО есть отображение множества обслуживаемых машин и существующих ограничений на выполнение работ в полевых условиях.

Отображение $\alpha$ представляет собой сочетание таких пар, когда каждый вид оборудования и оснастки $\left\{d_{i}\right\}$ агрегата соответствует выполняемой операции обслуживания $\left\{r_{i}\right\}$. Отображение $\beta$ представляет собой сочетание таких пар, когда каждое значение $\left\{r_{i}\right\}$ соответствует определённой 
обслуживаемой машине $\left\{m_{i}\right\}$. Множество всех упорядоченных троек образуют систему $\{\mathrm{S}\}$ в том и только в том случае, если $\left\{\left(d_{i} \alpha r_{i}\right) \bigcup\left(r_{i} \beta m_{i}\right)\right\}$.

Наглядно такую систему представим с помощью пространственной предметно-технологической матрицы или конфигуратора. Конфигуратором является часть сложного исследуемого объекта, полученная при его расчленении на более простые [1, 3]. Конфигураторы - альтернативные модели желаемой системы, позволяющие рассматривать систему с различных точек зрения - экономической, технологической и т.д. Пример конфигуратора для процесса конкретного номерного ТО машины $m_{i}$ представлен в виде таблицы 1 при $m_{i} \in M$. Рассматривая конфигураторы для процессов номерных ТО наиболее распространённых марок машин, можно определить полный перечень необходимой технологической оснастки и инструментов для АТО.

Таблица 1 - ФРАГМЕНТ КОНФИГУРАТОРА ДЛЯ ПРОЦЕССА НОМЕРНОГО ТЕХНИЧЕСКОГО ОБСЛУЖИВАНИЯ МАШИНЫ

\begin{tabular}{|c|c|c|c|c|c|}
\hline \multirow{2}{*}{$\begin{array}{c}\text { Категории } \\
\text { работ } r_{i}\end{array}$} & \multicolumn{5}{|c|}{ Виды оснастки и инструмента } \\
\cline { 2 - 6 } & $\begin{array}{c}\mathrm{d}_{1} \\
\text { (Воздуш- } \\
\text { ный ком- } \\
\text { прессор) }\end{array}$ & $\begin{array}{c}\mathrm{d}_{2} \\
\text { (Нагнета- } \\
\text { тель сма- } \\
\text { зок) }\end{array}$ & $\begin{array}{c}\mathrm{d}_{3} \\
\text { (набор } \\
\text { типа } \\
\text { ПИМ-15) }\end{array}$ & $\ldots$ & $\begin{array}{c}\mathrm{d}_{\mathrm{n}} \text { (модуль } \\
\text { КИ-28092.01- } \\
\text { ГОСНИТИ) }\end{array}$ \\
\hline$r_{1}$ (очистительные) & 1 & 0 & 0 & $\ldots$ & 0 \\
\hline$r_{2}$ (смазочные) & 1 & 1 & 0 & $\ldots$ & 0 \\
\hline$r_{3}$ (заправочные) & 0 & 0 & 0 & $\ldots$ & 0 \\
\hline $\begin{array}{c}r_{4} \text { (контрольно- } \\
\text { диагностические и } \\
\text { регулировочные) }\end{array}$ & 0 & 0 & 1 & $\ldots$ & 1 \\
\hline$r_{5}$ (проверка креплений) & 0 & 0 & 1 & $\ldots$ & 0 \\
\hline
\end{tabular}
$\mathrm{r}_{\mathrm{i}} \mathrm{d}_{\mathrm{i}}\left\{\begin{array}{l}1, \text { если выполнено условие }\left\{\left(\mathrm{d}_{\mathrm{i}} \alpha r_{i}\right) \cup\left(r_{i} \beta m_{i}\right)\right\} \\ 0, \text { если не выполнено условие }\left\{\left(\mathrm{d}_{\mathrm{i}} \alpha r_{i}\right) \cup\left(r_{i} \beta m_{i}\right)\right\}\end{array}\right.$

Функииональное описание агрегата ТО вначале рассмотрим в виде графической модели на рисунке 1 , где показано множество входов $\mathrm{X}_{\mathrm{k}}$ управляемых параметров системы и множество выходов $\mathrm{У}_{\mathrm{k}}-$ результатов 
реакции системы на управляющие воздействия или первичные обобщающие параметры функционирования. В качестве входных управляющих воздействий для сервисного средства наиболее значимыми являются $\mathrm{X}_{1}-$ виды выполняемых сервисных работ (функциональное назначение агрегата), $\mathrm{X}_{2}$ - тип транспортного средства, на котором базируется сервисная оснастка, $\mathrm{X}_{3}$ - типы сервисной оснастки, $\mathrm{X}_{4}$ - технология сервисных работ, $\mathrm{X}_{5}$ - исполнители работ, $\mathrm{X}_{6}$ - энергетическое обеспечение работ, $\mathrm{X}_{7}$ - организация работ.

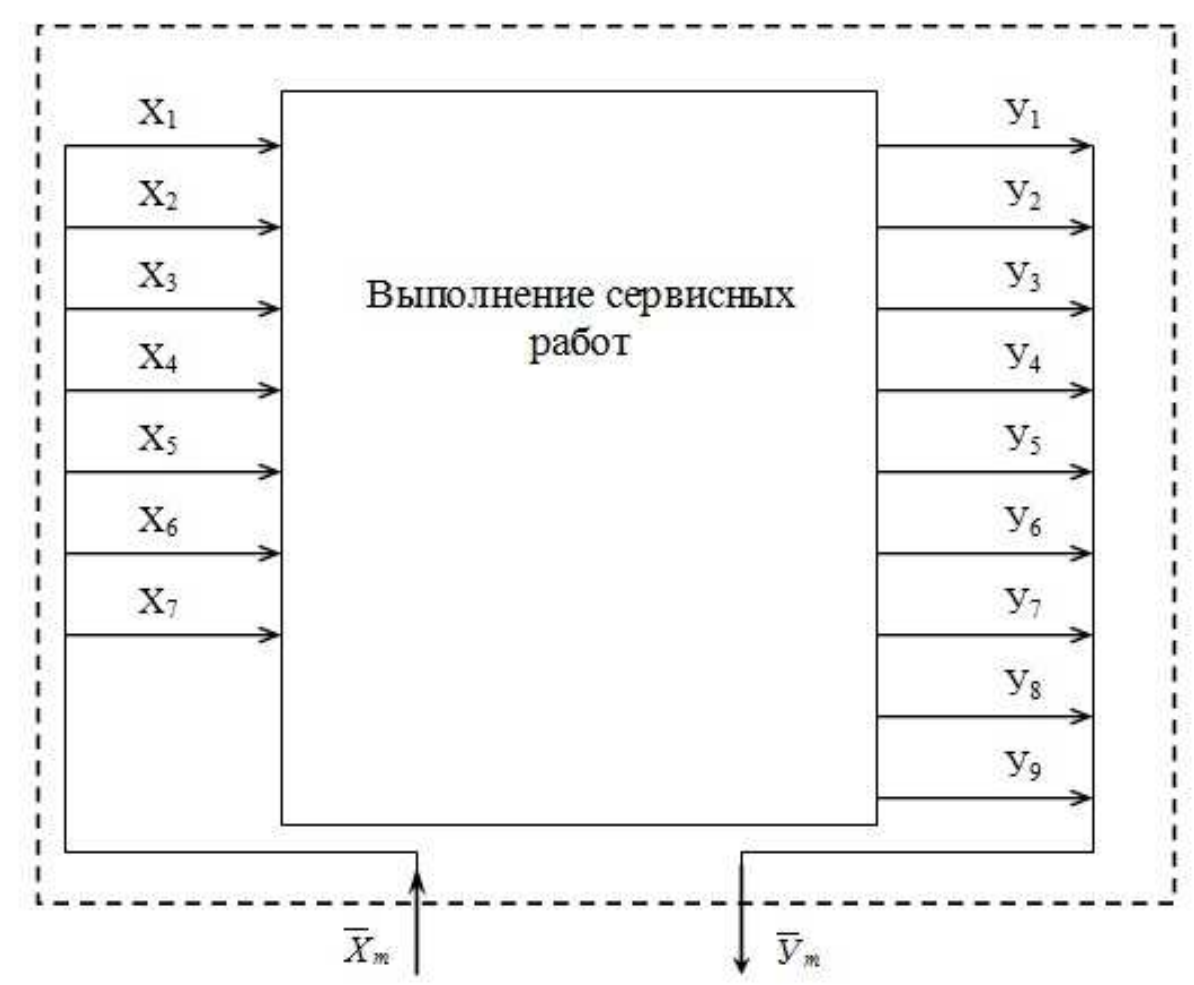

Рисунок 1 - Графическая модель функциональной системы - мобильное сервисное средство

Результатами реакции мобильного сервисного средства на перечисленные управляющие воздействия будут: $\mathrm{У}_{1}$ - коэффициент охвата регламентных работ, $\mathrm{У}_{2}$ - стоимость агрегата, $\mathrm{У}_{3}$ - занимаемый агрегатом объём (или площадь); $\mathrm{y}_{4}-$ масса агрегата, $\mathrm{y}_{5}$ - трудоёмкость работ, $\mathrm{y}_{6}-$ оперативность прибытия к месту работ, $\mathrm{y}_{7}$ - проходимость агрегата, $\mathrm{y}_{8}-$ коэф- 
фициент технической готовности парка обслуживаемых машин, $\mathrm{У}_{9}$ - себестоимость сервисных работ.

Функциональное описание агрегата ТО аналитически представляет собой соответствие

$$
\begin{gathered}
F \subseteq X+Y \\
\left\{(x, y) \mid x_{k} \in X, y_{k} \in Y\right\}
\end{gathered}
$$

где $x_{k}-$ множество входов (управляемые параметры системы);

$y_{k}$ - множество выходов (реакции объекта на управляющие воздействия);

$F$ - соответствие, связывающее параметры $x$ и $y$, и представляющее собой качество функционирования системы. Например: $y_{1}=F\left(X_{3}\right)$ зависимость коэффициента охвата регламентных работ от имеющихся типов сервисной оснастки; $V_{9}=F\left(X_{2}\right)$ - зависимость себестоимости сервисных работ от типа транспортного средства, на котором базируется сервисная оснастка и т.д.

Выделим наиболее значимые критерии математической модели для малогабаритного сервисного средства

$$
\begin{aligned}
& K_{o p} \rightarrow 1, \quad C_{A T O} \rightarrow \min , \\
& V \rightarrow \min , \quad m_{c} \rightarrow \min , \\
& C_{c p} \rightarrow \min ,
\end{aligned}
$$

где $K_{o p}-$ коэффициент охвата регламентных работ $\left(\mathrm{У}_{1}\right)$;

$C_{A T O}$ - стоимость сервисного средства $\left(\mathrm{У}_{2}\right)$, руб.

$V$ - объём, занимаемый сервисным средством $\left(\mathrm{У}_{3}\right), \mathrm{m}^{3}$;

$m_{c}$ - масса сервисного средства $\left(\mathrm{Y}_{4}\right), \kappa г$;

$C_{c p}$ - себестоимость сервисных работ $\left(\mathrm{У}_{9}\right)$, руб./час. 
Коэффициент охвата регламентных работ для $i$-го вида ТО конкретной машины представляет собой отношение фактического количества сервисных операций $N_{\phi}^{i}$, которые можно выполнить с помощью передвижного средства, к общему количеству регламентных операций $N_{p}^{i}$ в рассматриваемом $i$-том техническом облуживании

$$
K_{o p}^{i}=\frac{N_{\phi}^{i}}{N_{p}^{i}} .
$$

Стремление данного критерия к единице означает, что агрегат ТО позволит выполнить все регламентные операции конкретного ТО по машине заданной марки. Стоимость, занимаемый объём (или площадь) и масса сервисного средства будут определяться характеристиками используемого сервисного оборудования и инструментов. Подбор соответствующего оборудования и варианты его монтажа также определяют тип самого АТО и используемого транспортного средства. Анализ конфигураторов для ЕТО и ТО-1 отечественных тракторов и комбайнов при условии $K_{o p}=1$ позволил нам выбрать необходимый перечень сервисного оборудования и составить структурную схему перспективного АТО (рисунок 2).

Здесь не учитывается заправочное оборудование, поскольку заправка машин топливом и маслам в полевых условиях осуществляется специальным заправочным агрегатом. Данная схема предусматривает модульный принцип компоновки оснастки для прицепного или навесного типа АTO. Энергетический модуль агрегата содержит воздушный компрессор и автономный электрогенератор. Изначально мы рассматриваем привод компрессора от ВОМ трактора, но здесь также может быть вариант комбинированного привода от ВОМ трактора и от автономного электрогенератора. Модуль средств технической диагностики, модуль универсального инструмента и бак для технической воды на схеме не имеют функциональных связей с другими модулями и элементами АТО. Их объединяет техно- 
логическая связь, показанная на схеме рисунка 2 в виде технологических контактов с обслуживаемым объектом.

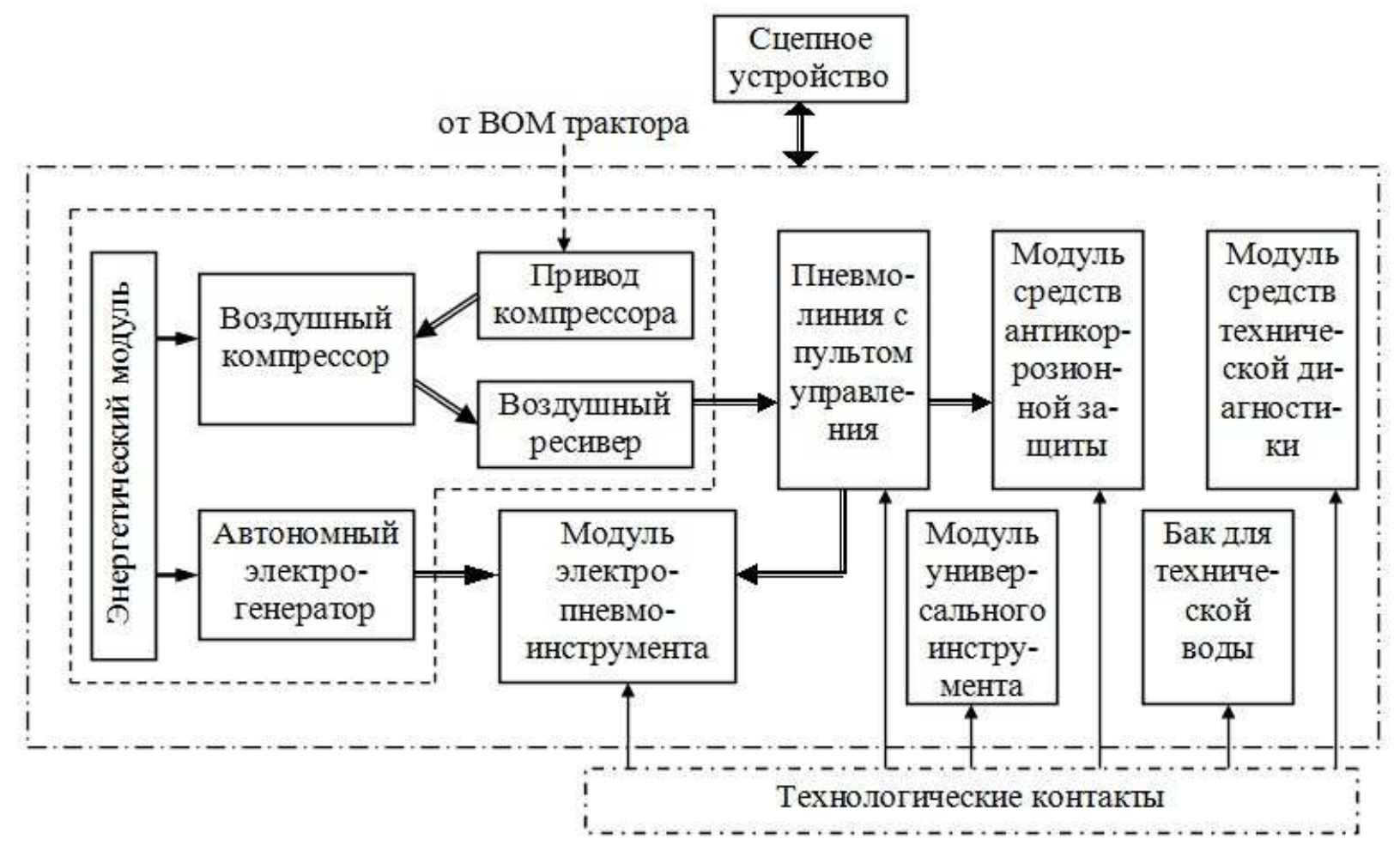

Рисунок 2 - Структурная схема перспективного АТО

Дальнейшее определение типа АТО и критериев (3) связано с анализом габаритов, массы и стоимости имеющегося на современном рынке сервисного оборудования и инструментов. Нами были определены основные статистические характеристики этих показателей для отдельных сервисных модулей и элементов АТО. Вся оснастка при её размещении в $2 \div 3$ яруса по вертикали занимает площадь около одного квадратного метра, имеет массу $250 \div 300$ кг, а её стоимость варьирует в пределах $150 \div 190$ тыс. руб. В данном случае применение в качестве транспортного средства грузового автомобиля или тракторного прицепа будет нерациональным, так как масса сервисной оснастки составляет не более $10 \%$ их грузоподъёмности, а площадь их кузова будет заполнена не более, чем на 20\%. Практические результаты монтажа перечисленных объектов показывают, что вся 
оснастка АТО может быть размещена на несущей раме, которая навешивается на трактор класса 1,4. Габарит несущей рамы по ширине не превышает разрешённых значений для передвижения по дорогам общего пользования, а масса агрегата $m_{c}$ не превышает грузоподъёмности основной гидросистемы трактора данного тягового класса.

Для навесного типа агрегата ТО особенно важным является равномерное распределение сервисной оснастки на несущей раме, поскольку это позволит исключить дисбалансы в транспортном положении агрегата. Значительное смещение центра масс агрегата относительно навесного устройства может привести к опрокидыванию агрегата при его движении на склонах, а также будет приводить к деформации рамы АТО и снижению peсурса сцепного устройства. По аналогии с исследованиями [4] нами предлагается алгоритм компоновки сервисной оснастки на раме навесного агрегата, при условии аппроксимации форм отдельных модулей и аппаратов простыми геометрическими фигурами - параллелепипед и цилиндр. Реализация данного алгоритма предусматривает не только рациональное размещение сервисных модулей и отдельных конструктивных элементов на раме АТO, но и определение варианта с минимальной стоимостью металлоконструкции рамы и защитного каркаса АТО. Выполнение алгоритма осуществляется для ранее выбранных сервисных модулей с известными их стоимостными, геометрическими и другими параметрами.

В основе предлагаемого алгоритма компоновки оснастки рассматривается прямоугольная система координат $X Y Z O$ с метрикой пространства $\rho$

$$
\rho\left(c^{\prime}, c^{\prime \prime}\right)=\left|X_{C^{\prime}}-X_{C^{\prime \prime}}\right|+\left|Y_{C^{\prime}}-Y_{C^{\prime \prime}}\right|+\left|Z_{C^{\prime}}-Z_{C^{\prime \prime}}\right|,
$$

где $\rho\left(c^{\prime}, c^{\prime \prime}\right)$ - расстояние между двумя точками $c^{\prime}$ и $c^{\prime \prime}$ пространства XYZO.

Основание системы координат $O$ совмещено с нижним углом пространства, совпадающим с углом рамы на передней стенке АТО (рисунок 3). Пространственное положение $i$-го модуля задаётся вектором $A_{i}=\left(X_{i}, Y_{i}\right.$, 
$\left.Z_{i}, Q_{i}\right)$, где $X_{i}, Y_{i}, Z_{i},-$ координаты центра основания модуля или отдельного аппарата, $Q_{i}$ - угол поворота аппарата или модуля относительно начального положения.

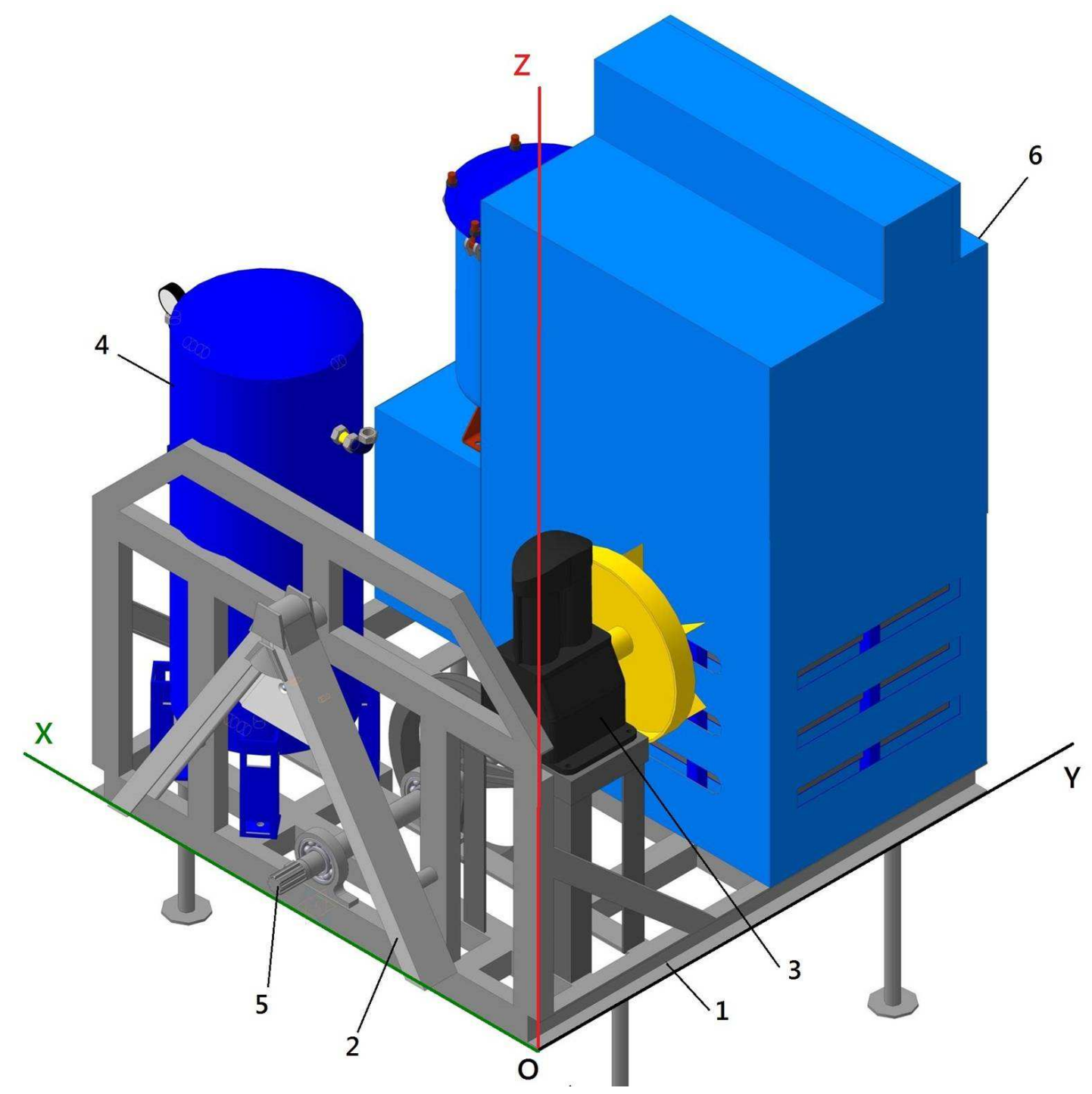

1 - несущая рама; 2 - замок автосцепного устройства; 3 - воздушный компрессор; 4 - ресивер; 5 - вал с клиноремённым приводом;

6 - инструментальный шкаф с сервисными модулями

Рисунок 3 - Компоновка сервисной оснастки навесного агрегата ТО

Обозначим $A=\left\{A_{i} \mid i=\overline{1, N}\right\}$ - вариант размещения оснастки; $C=\left(X_{C}\right.$, $\left.Y_{C}, Z_{C}\right)$ - вариант металлоконструкции рамы и каркаса ATO (инструментального шкафа), где $X_{C}, Y_{C}, Z_{C}$ - соответственно ширина, длина и высота 
ATO; $h=(A, C)$ - вариант компоновки, $h \in H \subset D$, где $H-$ множество допустимых вариантов компоновки, $D$ - множество всех возможных вариантов компоновки. Модель проектного решения МПР, выделяющая множество $H$, является отображением $M П Р: D \rightarrow H$ или $H=M \Pi P(D)$.

С учётом приведенных обозначений задача оптимальной компоновки оснастки AТО содержит поиск такого варианта компоновки, который будет соответствовать минимуму целевой функции

$$
h^{*}=\arg \min \{Ц(h)|h \in H|=M \Pi P(D)\} .
$$

В качестве целевой функции Ц здесь могут выступать критерии (3) объём $V$ металлоконструкции рамы и каркаса АТО или его стоимость $C_{A T O}$. При этом ставится условие достижения минимального дисбаланса конструкции АТО в навешенном состоянии относительно навесного устройства трактора.

В данной статье мы не будем приводить полностью описание математической модели задачи компоновки и методологию её решения. Опишем лишь некоторые ограничения, принимаемые во внимание при решении задачи:

- ограничение на предельно допустимые размеры агрегата

$$
X_{C}^{\min } \leq X_{C} \leq X_{C}^{\max } ; \quad Y_{C}^{\min } \leq Y_{C} \leq Y_{C}^{\max } ; \quad Z_{C}^{\min } \leq Z_{C} \leq Z_{C}^{\max } ;
$$

- тяжёлое оборудование размещается на нижних ярусах;

- для ремонта и обслуживания несъёмного сервисного оборудования должны быть предусмотрены специальные пространства;

- пульт управления пневмосистемой агрегата должен быть доступным для оператора и иметь хороший обзор.

Максимальные габаритные размеры мобильного АТО ограничиваются действующими правилами дорожного движения. Для упрощения задачи можно принять конструктивно минимальный размером $X_{C}^{\min }$ по ширине, например, равным расстоянию между задними колёсами трактора. Тогда 
при известном диапазоне значений ширины $X_{C}$ и массе сервисных модулей можно определить поперечное сечение балок рамы и каркаса для заданного материала, что является исходными данными для расчёта стоимости ATO. Укрупненная блок-схема алгоритма компоновки множества $N$ оснастки для $k$ ярусов (уровни) и $j$ рядов показана на рисунке 4.

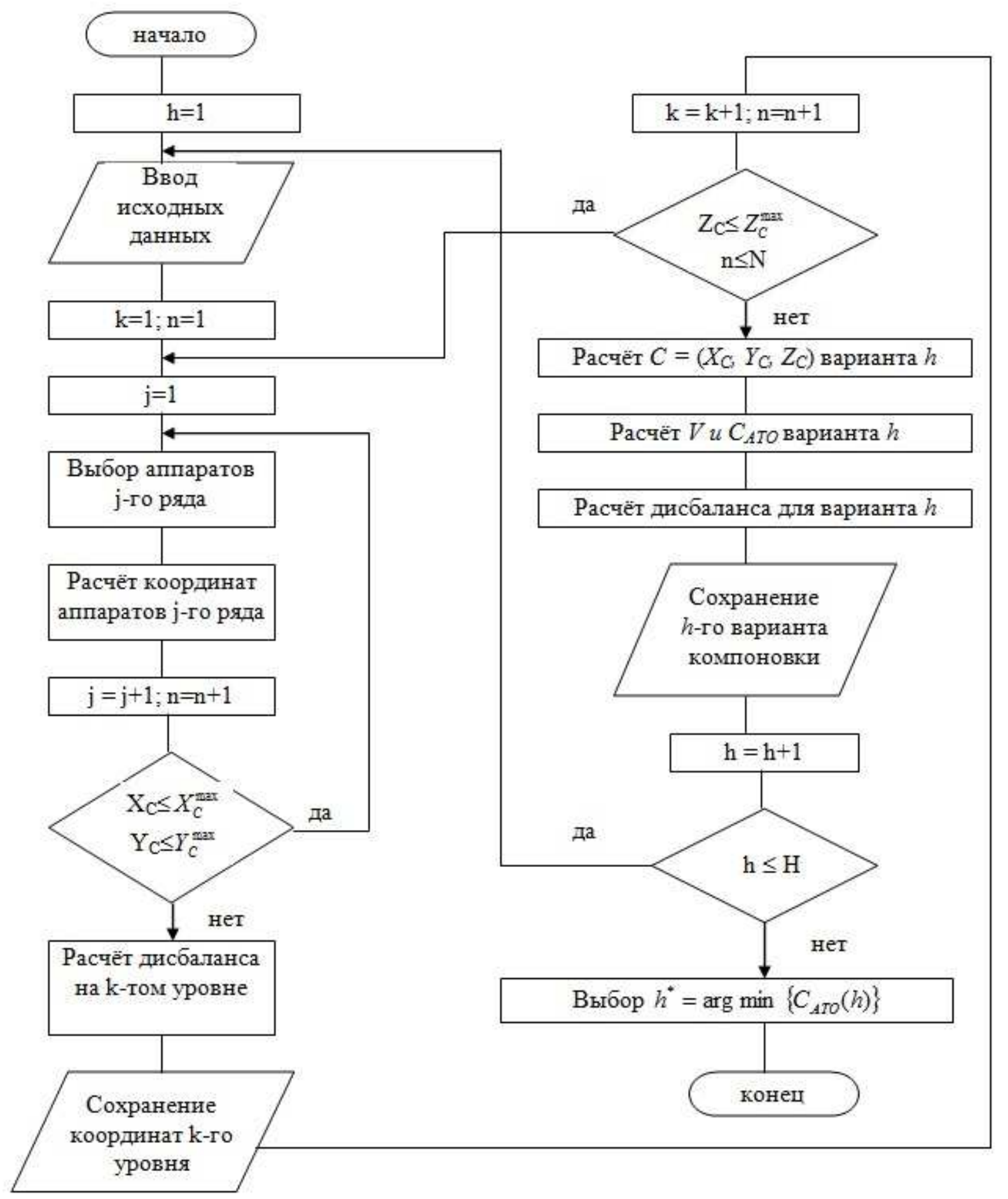

Рисунок 4 - Укрупнённая блок-схема алгоритма компоновки АТО 
После каждого варианта компоновки $h_{i}$ выполняется расчёт занимаемого агрегатом объёма $V$ и стоимости агрегата $C_{A T O}$. Для автоматизации предлагаемого алгоритма мы в настоящий момент разрабатываем программное обеспечение. Предварительная реализация алгоритма компоновки позволила получить значения $X_{C}=1120$ мм, $y_{C}=1250$ мм, $Z_{C}=1360$ мм. Группа критериев (3) для полученного малогабаритного агрегата имеет следующие значения $K_{o p}=1 ; V=1,9 \mathrm{~m}^{3} ; m_{c}=420$ кг; $C_{A T O}=190 \div 225$ тыс. руб. Занимаемая агрегатом площадь $-1,4 \mathrm{~m}^{2}$.

\section{Внедрение и оценка эффективности результатов}

Используя результаты данных теоретических исследований, мы изготовили экспериментальный образец навесного агрегата технического обслуживания - АТОН, который запатентовали как полезную модель $[6,8]$. В настоящий момент данный агрегат проходит государственные квалификационные испытания в ФГБУ «Северо-Кавказская МИС» (г. Зерноград).

Для проектируемого сервисного средства необходимо прогнозировать его технико-экономические показатели. Важный экономический критерий себестоимость сервисных работ $C_{c p}$, выполняемых с помощью агрегата ТО, можно определять по выражению [2]

$$
C_{c p}=\frac{C_{3 n}+C_{c o}+C_{M 3}+C_{T P}+A+C_{T O P}}{T_{2}},
$$

где $C_{\text {зn }}$ - зарплата исполнителей работ, руб.;

$C_{c o}$ - социальные отчисления, руб.;

$C_{\text {мз }}$ - материальные затраты на технологию сервисных работ (прямые расходы), руб.;

$C_{T P}$ - затраты на перемещение агрегата ТО (транспортные расходы), руб.;

$A$ - амортизация сервисного оборудования и транспортного средства, руб.; 
$C_{T о P}$ - отчисления на текущий ремонт и ТО сервисного оборудования и транспортного средства, руб. (прочие расходы);

$T_{\text {z }}$ - годовая загрузка агрегата ТО, час.

Месячные отчисления в пенсионный фонд, на медицинское и социальное страхование определяются как сумма

$$
\Pi \Phi C=\frac{3 \Pi}{100} \cdot\left(P_{\Pi \Phi}+P_{M C}+P_{C C}\right)
$$

где $P_{\Pi \Phi}=22 \%, P_{M C}=5,1 \%, P_{C C}=2,9 \%$ - процентные ставки отчислений соответственно в пенсионный фонд, на медицинское и социальное страхование.

Материальные затраты на технологию сервисных работ можно представить как

$$
C_{\text {м3 }}=C_{1}+C_{2}+C_{3}+C_{4}+C_{5}+C_{6},
$$

где $C_{1}$ - затраты на материалы, руб.; $C_{2}$ - затраты на запчасти, руб.;

$C_{3}$ - топливо и энергия на технологию, руб.; $C_{4}-$ вода на технологию, руб.; $C_{5}$ - сжатый воздух на технологию, руб.; $C_{6}$ - вспомогательные материалы, руб.

Годовая загрузка $T_{\text {z }}$ агрегата соответствует плановой годовой трудоёмкости ЕТО и ТО-1 машин в хозяйстве. В исследованиях [5] нами были определены значения этой трудоёмкости для различных парков машин, состоящих из отечественных тракторов марок К-700А, Беларус и ХТЗ-150, а также комбайнов производства завода Ростсельмаш (таблица 4).

Результаты расчёта себестоимости сервисных работ для предлагаемого навесного агрегата АТОН показаны на графике рисунка 5. Здесь же для сравнения представлена себестоимость работ при использовании серийных агрегатов на базе грузового автомобиля и тракторного прицепа. 
Таблица 4 - ПЛАНОВЫЕ ГОДОВЫЕ ТРУДОЁМКОСТИ ЕТО И ТО-1 ДЛЯ РАЗЛИЧНЫХ ПАРКОВ ОБСЛУЖИВАЕМЫХ МАШИН

\begin{tabular}{|l|c|c|c|c|c|}
\hline \multirow{2}{*}{ Показатель } & \multicolumn{5}{|c|}{ Вариант парка обслуживаемых машин } \\
\cline { 2 - 6 } & А & Б & В & $\Gamma$ & Д \\
\hline $\begin{array}{l}\text { Количество } \\
\text { тракторов, шт. }\end{array}$ & 3 & 6 & 10 & 13 & 20 \\
\hline $\begin{array}{l}\text { Количество } \\
\text { комбайнов, шт. }\end{array}$ & 1 & 3 & 5 & 7 & 10 \\
\hline $\begin{array}{l}\text { Трудоёмкость } \\
\text { ТО, чел-ч. }\end{array}$ & 70 & 165 & 280 & 371 & 555 \\
\hline
\end{tabular}

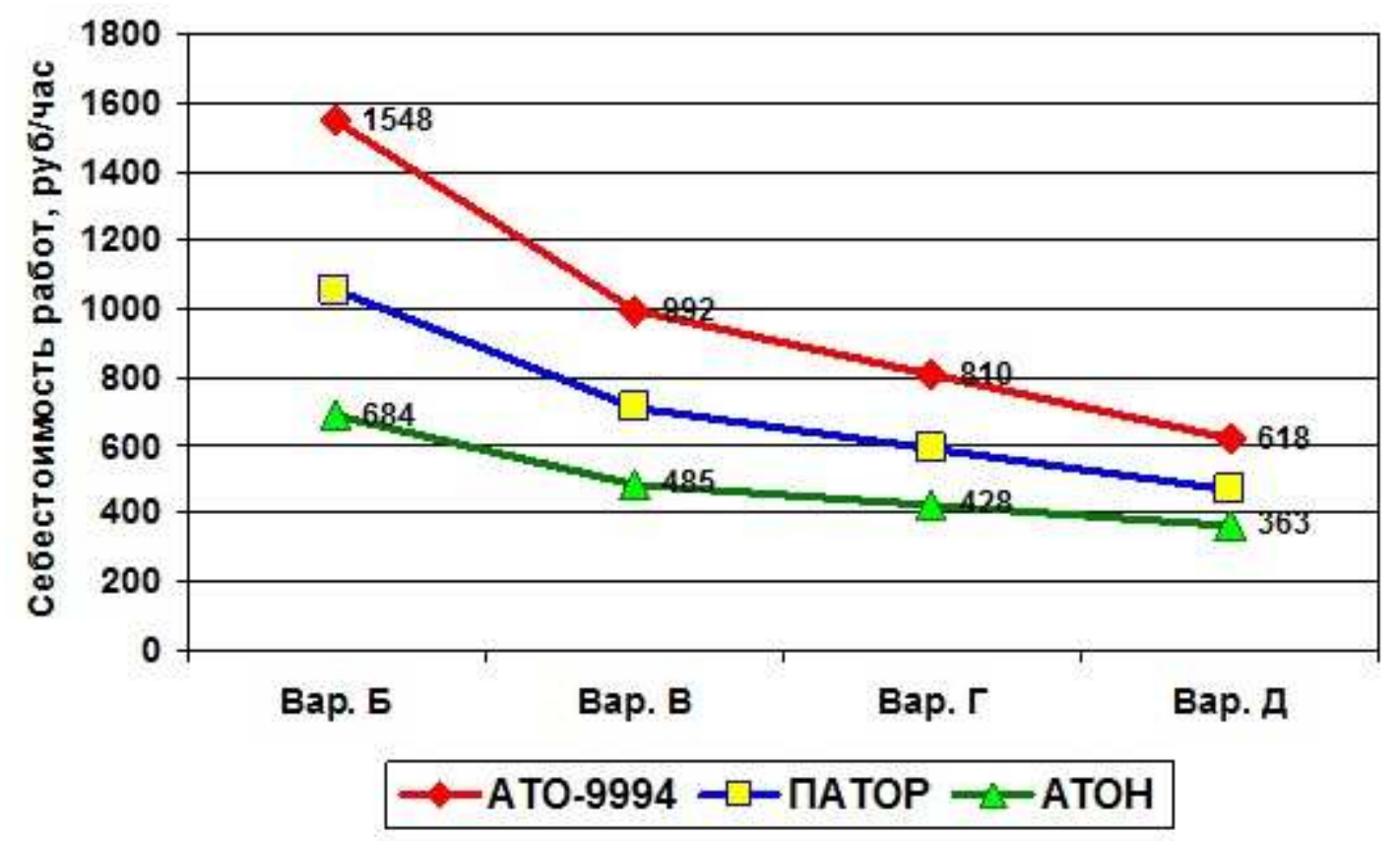

Рисунок 5 - Зависимость себестоимости работ по ЕТО и ТО-1 для различных агрегатов ТО от количества обслуживаемых машин

\section{Заключение}

1. Предлагаемый математический подход позволяет обосновать состав технологической оснастки малогабаритного агрегата технического обслуживания, определять его геометрические параметры, типаж и технико-экономические показатели в условиях сельхозпредприятий. 
2. Алгоритм компоновки сервисной оснастки обеспечивает достаточную точность расчётов координат модулей. Монтаж экспериментального агрегата показал, что их отклонения не превышают $2 \%$.

3. Использование малогабаритного навесного агрегата ТО позволит в 3,8 раза снизить металлоёмкость конструкции и в 3 раза снизить стоимость агрегата по сравнению с прицепными аналогами. При этом себестоимость сервисных работ снижается в 1,3 раза по сравнению с прицепным аналогом и в 1,7 раза по сравнению с агрегатами на шасси автомобиля.

Литература

1. Авербух, С.Л. Ремонтное предприятие как объект системного анализа // Механизация и электрификация сельского хозяйства, 1981, №10, с. 55-57

2. Конкин Ю.А. Экономика технического сервиса на предприятиях АПК. - М.: КолосС, 2005. - 368 с.

3. Лефевр, В.А. Конфликтующие структуры. Изд. 2-е, перераб. и доп. - М.: Издво «Советское радио», 1973. - 158 с. с ил.

4. Малыгин, Е.Н. Методология автоматизированного проектирования компоновки оборудования химических производств / Е.Н. Малыгин, С.Я. Егоров, В.А. Немтинов, М.С. Громов [Текст] // Вестник ТГТУ. - 2006. Том 12. - № 2А. - С. 344-362

5. Никитченко, С.Л. Выбор исполнителей и средств технического сервиса машин в сельскохозяйственном производстве / С.Л. Никитченко, С.В. Смыков, Н.П. Жиляскова [Текст] // Вестник аграрной науки Дона. - 2015. - №2. - С. 21-29

6. Никитченко, С.Л. Навесной агрегат для технического обслуживания и ремонта машин / С.Л. Никитченко, С.В. Смыков [Текст] // Техника в сельском хозяйстве. 2014. - № 4. - С. 21-23

7. Никитченко, С.Л. Совершенствование специализированного технического обслуживания техники в сельхозпредприятиях / С.Л. Никитченко, С.В. Смыков [Текст] // Механизация и электрификация сельского хозяйства. - 2014. - №6. - С. 25-28

8. Патент на полезную модель № 145187, Россия. "Навесной агрегат технического обслуживания и ремонта «АТОН»" / Никитченко С.Л. Зарегистрировано в РОСПАТЕНТ 06.08.2014. Заявка №2014107390.

\section{References}

1. Averbuh, C.L. Remontnoe predprijatie kak ob\#ekt sistemnogo analiza // Mehanizacija i jelektrifikacija sel'skogo hozjajstva, 1981, №10, s. 55-57

2. Konkin Ju.A. Jekonomika tehnicheskogo servisa na predprijatijah APK. - M.: Ko$\operatorname{los} \mathrm{S}, 2005 .-368 \mathrm{~s}$.

3. Lefevr, V.A. Konfliktujushhie struktury. Izd. 2-e, pererab. i dop. - M.: Izd-vo «Sovetskoe radio», 1973. - 158 s. s il.

4. Malygin, E.N. Metodologija avtomatizirovannogo proektirovanija komponovki oborudovanija himicheskih proizvodstv / E.N. Malygin, S.Ja. Egorov, V.A. Nemtinov, M.S. Gromov [Tekst] // Vestnik TGTU. - 2006. Tom 12. - № 2A. - S. 344-362 
5. Nikitchenko, S.L. Vybor ispolnitelej i sredstv tehnicheskogo servisa mashin $\mathrm{v}$ sel'skohozjajstvennom proizvodstve / S.L. Nikitchenko, S.V. Smykov, N.P. Zhiljaskova [Tekst] // Vestnik agrarnoj nauki Dona. - 2015. - №2. - S. 21-29

6. Nikitchenko, S.L. Navesnoj agregat dlja tehnicheskogo obsluzhivanija i remonta mashin / S.L. Nikitchenko, S.V. Smykov [Tekst] // Tehnika v sel'skom hozjajstve. - 2014. № 4. - S. 21-23

7. Nikitchenko, S.L. Sovershenstvovanie specializirovannogo tehnicheskogo obsluzhivanija tehniki v sel'hozpredprijatijah / S.L. Nikitchenko, S.V. Smykov [Tekst] // Mehanizacija i jelektrifikacija sel'skogo hozjajstva. - 2014. - №6. - S. 25-28

8. Patent na poleznuju model' № 145187, Rossija. "Navesnoj agregat tehnicheskogo obsluzhivanija i remonta «ATON»" / Nikitchenko S.L. Zaregistrirovano v ROSPATENT 06.08.2014. Zajavka №2014107390. 